\title{
Research and Practice of Monitoring Measurement Security Technology of Portal Excavation for Mountain Tunnel
}

\author{
Shiyu WEI \\ Chongqing Engineering Research Center of Automatic \\ Monitoring for Geological Hazards \\ Chongqing Institute of Geology and Mineral Resources \\ Chongqing, China \\ e-mail: 1832382150@qq.com
}

\section{Jun JIANG}

Chongqing Engineering Research Center of Automatic

Monitoring for Geological Hazards

Chongqing Institute of Geology and Mineral Resources

Chongqing, China

e-mail: jiangjun_dyy@163.com

\author{
Chuan LI \\ Chongqing Engineering Research Center of Automatic \\ Monitoring for Geological Hazards \\ Chongqing Institute of Geology and Mineral Resources \\ Chongqing, China \\ e-mail: 641419444@qq.com
}

\section{Chao LI}

Chongqing Engineering Research Center of Automatic Monitoring for Geological Hazards

Chongqing Institute of Geology and Mineral Resources Chongqing, China

e-mail: 391636485@qq.com

\section{Pengfei LU \\ Chongqing Institute of Geological Environment Monitoring \\ Chongqing, China \\ e-mail: 402443685@qq.com}

\begin{abstract}
In the construction process of portal excavation for mountain tunnels, the improper risk management and control result in the instability of the front slope, deformation of the tunnel portal and subsidence of the roof. In order to carry out the purport of dynamic design and informationalized construction, ensuring the quality and security of portal construction, a three-dimensional and multi-level monitoring measurement system is indispensable. Combining with the practical monitoring measurement of the portal excavation of the tunnel exit in a mountain tunnel in Chongqing, the monitoring measurement system construction process of portal excavation for mountain tunnels is expounded. Besides, the portal stability analysis method and the monitoring information feedback procedure based on multi-source data for the three-dimensional and multi-level monitoring measurement system are analyzed.
\end{abstract}

Keywords-mountain tunnel; portal excavation; monitoring measu rement; stability analysis; information feedback

\section{INTRODUCTION}

As the important component of transportation network including railway, highway and urban subway, tunnel is also the basic form of underground space utilization [1]. Mountain tunnels, which connect plenty of cities, are the traffic tunnels across mountains and are able to transport both passengers and goods. However, the complicated geological conditions and construction surroundings bring about much trouble for tunnel construction quality and security. As one of the three elements of the new austrain tunnel construction method, monitoring and measurement play an essential role in informationalized tunnel construction and ensuring construction security. Consequently, monitoring and measurement are the job of great concern [2].

In the process of mountain tunnel construction, portal excavation and support are the initial procedures, and their construction schedule and quality directly influence the excavation schedule and construction security inside the tunnel. With the improvement of environmental awareness and advancement of construction technology, the portal forms of mountain tunnels become diverse while some problems appear frequently, including instability of the front slope in the portal, subsidence in the tunnel roof and deformation in the portal. For the construction security, carrying out the purport of dynamic design and informationalized construction, as well as establishing a three-dimensional and multi-level monitoring measurement system, is particularly important. Therefore, based on the practical monitoring measurement of portal excavation in the tunnel exit of a mountain tunnel in Chongqing, the monitoring measurement construction process of portal excavation for mountain tunnel is explained. In addition, the stability analysis method and the monitoring information feedback procedure based on multi-source data for the threedimensional and multi-level monitoring measurement system are analyzed, providing a security blanket for portal excavation in mountain tunnels and references for similar projects. 


\section{ENGINEERING BACKGROUND}

\section{A. Engineering Situation}

The second section $(\mathrm{K} 5+300 \sim \mathrm{K} 11+594)$ of the mountain tunnel in Chongqing mainly includes the following parts. The left line $(\mathrm{ZK} 5+300 \sim \mathrm{ZK} 9+685)$ is 4385 meters long while the right line is 4395 meters long. Besides, there is $2 \#$ underground ventilator room and $2 \#$ ventilation inclined shaft $(\mathrm{X} 2 \mathrm{~K} 0+000 \sim \mathrm{X} 2 \mathrm{~K} 1+145)$ with the length of 1145 meters. Moreover, there are 2\# bridge, 3\# bridge, $4 \#$ bridge and Wanzhou connection road.

\section{B. Geological Environmental Conditions}

The tunnel exit is located at a slope which is north of Wanzhou Changping machinery. The elevation of the exit is about 427.58 meters. The slope aspect is $\mathrm{S} 38^{\circ} \mathrm{E}$ and the terrain slope is $15^{\circ} \sim 30^{\circ}$. The overlying residual clinosol solum is silty clay with gravel and the thickness is 1.2 7.9 meters. The underlying bedrock is mud stone with sands tone. The intensely weathered zone is as thick as 3.6 8.9meters. The groundwater level in tunnel exit is 1.2 7.9 meters and the water table is $430.8 \sim 424.1$ meters.

The structure of the slope in the exit is consequent slope with the terrain slope of $15^{\circ} \sim 30^{\circ}$. It is soil-rocky bedding slope. The surface soil layer is silty clay with gravel and the thickness is $2 \sim 5$ meters. Under the overburden is mud stone with sandstone. The dip angle of strata level is $58^{\circ}$. The lower bedrock is mud stone with sandstone in lower Shaximiao formation of middle Jurassic (J2xs), and the inclination direction is $147^{\circ}$ while the dip angle is $35^{\circ}$. The overall slope situation is stable. The slope that the elevation is over 440 meters is sporadically distributed with residual clinosol solum with the thickness of $0.4 \sim 0.8$ meters. The solum is also stable.

\section{Portal Design Form}

The design of tunnel portal should follow the principle of get in early and get out late and the idea of safe, economic, concordant and natural. Considering the capacious portal space and the gentle slope distributed with loose accumulation on the surface, both left and right lines in tunnel exit are designed as the form of bamboo cutting to avoid large area of slope cutting and as shown in Figure 1.

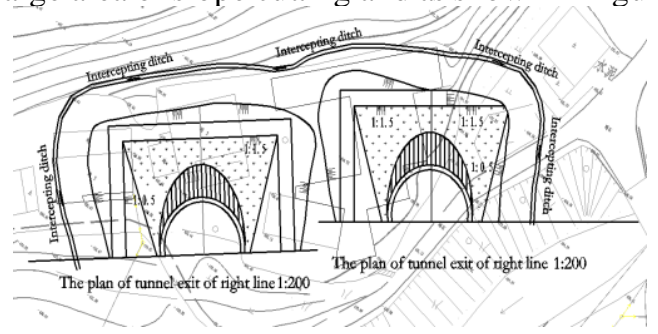

Figure 1. The plan of portal design in tunnel exit

\section{Risk Source Analysis}

\section{1) Tunnel body in the exit:}

The surrounding rocks of left and right lines are $\mathrm{J} 2 \mathrm{x} 2$ sandstone with shale, with strong to moderate weathering. The surrounding rocks are relatively soft rocks with developed fractures and broken rocks. The overlying strata on the roof are relatively thin, the part of that is solum and it is shallow-buried section which has a bad tunneling condition. The arch is likely to collapse when there is no support. The jamb wall is easily to loss stability and fallblock occurs easily. Additionally, the groundwater level is higher than the roof, which may leads to linear flowing water, seepage and drip. Because the thickness of the left tunnel mountain is obviously less than that of the right, eccentric compression may be appeared related to the terrain.

2) Slope and front slope in tunnel exit:

After the excavation in tunnel exit, there are two soilrocky slopes at the left and right of the exit with the thickness of 5 10 meters. The slopes are bedded structure with two groups of fractures. The inclination of the intersecting line of fracture L1 and fracture L2 is $335^{\circ}$ and the dip angle is $38^{\circ}$. Meanwhile, a soil-rocky slope appears on the roof of the exit with the dip angle of $15^{\circ} \sim 20^{\circ}$. The surface soil layer is $2 \sim 5$ meters. Furthermore, under the overburden is a bedded slope of mud stone with sandstone. The aspect of it is $142^{\circ}$ and the strata occurrence is $150^{\circ} \angle 58^{\circ}$. The above mentioned slopes and front slopes should be supported after excavation.

3) Natural gas pipeline in the roof of tunnel exit:

There is a natural gas pipeline of China National Petroleum Corporation in Wanzhou operation area, which is orthogonal to the tunnel, at the back edge of the front slope in the roof of the tunnel exit. The diameter of the pipeline is 110 millimeters and the burial depth is less than 1 meter. The daily delivery value reaches 150 thousand cubic meters. Meanwhile, the gas pressure is $9 \mathrm{MPa}$ and the gas is harmful gas without desulfidation. As the shallow burial depth of the natural gas pipeline and the relatively thick overlying strata, the protection of the pipeline should be strengthened in the tunnel cons truction.

\section{CONST RUCTION OF MONITORING MEASUREMENT SYSTEM}

The field monitoring measurement is an important part of the design and construction of the new austrian tunneling method. It is able to guide the construction, forecast the dangerous cases, ensure the safety and obtain deformation and stability status of surrounding rocks and supporting structure by monitoring data analysis, providing information and bases for structure design optimization, supporting parameter and construction technology. Besides, it is capable to accumulate data for tunneling engineering design and construction. Therefore, in the process of portal excavation of tunnel construction, carrying out monitoring and measurement is considerably important.

\section{A. Construction Principle of Monitoring Measurement System}

The construction of monitoring measurement system mainly follows the principles below [1].

1) Principle of reliability:

Reliable instruments are necessary for monitoring system, and measuring points should be protected during the monitoring at the same time. 


\section{2) Principle of multi-level monitoring:}

The monitoring object is given priority to displacement while giving consideration to other monitoring projects. In terms of monitoring methods, instrument monitoring is the main method, supplemented by patrol. Measure points should be stationed in shallow buried surface, areas close to buildings and above underground pipelines respectively, forming a monitoring network covering a certain number of measure points.

3) Principle of monitoring priority on key areas:

Monitoring point arrangement should be reasonable. The relationship between time and space should be paid attention to, and the key parts should be controlled. Besides, the deformation monitoring frequency in the areas close to tunnel face should be improved.

4) Principle of convenience and practice:

To reduce the interference between monitoring and construction, the installation and measurement of monitoring system should be as convenient and practical as possible.

\section{B. Original Data for Monitoring Measurement}

Before monitoring, engineering situation, conditions related to hydrology, geology, transportation and climate in monitoring areas, construction design and organization should be appreciated adequately. Therefore, the basic data in TABLE I are needed in the process of monitoring measurement system construction [3].

\section{Monitoring Contents and Methods}

The determination of the contents and methods of monitoring should follow the basic principles mentioned in III-A. They should be determined with comprehensive analysis and adequate understanding of geological and hydrological conditions around the portal, specific risk sources, construction design and organization. Therefore, the following monitoring projects and methods listed in TABLE are formulated according to the conditions around the portal in the tunnel exit.

\section{Layout of Measure Points}

1) Observation of geology and support condition:

After each blasting excavation, the relevant circumstances and phenomena obtained from geological observation, geological sketch, and photography or camera technology are recorded in detail. In the observation, the discovery time, specific mileage position as well as the description of abnormal phenomenon must be recorded in detail when the abnormal phenomenon is found.

2) Horizontal convergence and crown settlement:

According to the requirements of relevant specifications [4], the layout of measure points for horizontal convergence and crown settlement, in terms of the excavation construction of benching tunneling method, is implemented according to Figure 2.

3) Three-dimensional surface displacement monitoring of shallow layer in front slope:

The measure points are positioned mainly in the portal section where the top of front slope is perpendicular to the tunnel center line. In the tunnel area, points are positioned every 2 meters from the crown with bilateral symmetry. In the area less than $45^{\circ}$, points are positioned every 4 meters with bilateral symmetry, as shown in Figure 3.

\section{TABLE I. BASIC DATA FORTUNNEL MONITORING MEASUREMENT}

\begin{tabular}{|c|l|}
\hline $\begin{array}{c}\text { Serial } \\
\text { number }\end{array}$ & \multicolumn{1}{c|}{ Name of data } \\
\hline 1 & Geological investigation reports of tunneling engineering \\
\hline 2 & Documents of construction drawing design \\
\hline 3 & Documents of construction organization \\
\hline 4 & $\begin{array}{l}\text { Specifications for highway tunnel design, Specifications } \\
\text { for construction technology of highway tunnels }\end{array}$ \\
\hline
\end{tabular}

TABLE II. THE MAIN MONITORING PROJECTS DURING THE PORTAL EXCAVATIO

\begin{tabular}{|c|c|c|c|}
\hline Serial number & Name of project & Monitoring method & Monitoring purpose \\
\hline 1 & $\begin{array}{l}\text { Observation of geology and } \\
\text { support condition }\end{array}$ & $\begin{array}{l}\text { Geological observation, } \\
\text { geological sketch, photography } \\
\text { or camera technology }\end{array}$ & $\begin{array}{l}\text { Master of the occurrence of surrounding strata, } \\
\text { structure plane characteristics, karst caves, faults and } \\
\text { seepage conditions of portal and front slope, observe } \\
\text { fractures of support structure }\end{array}$ \\
\hline 2 & $\begin{array}{l}\text { Horizontal convergence } \\
\text { monitoring of portal }\end{array}$ & $\begin{array}{l}\text { Various types of convergence } \\
\text { gauges }\end{array}$ & $\begin{array}{l}\text { Obtain the convergence trend of tunnel portal and } \\
\text { sections of tunnel exit, influence of eccentric } \\
\text { compression of slope and front slope on the trend }\end{array}$ \\
\hline 3 & $\begin{array}{l}\text { Crown settlement } \\
\text { monitoring }\end{array}$ & Trigonometric leveling & $\begin{array}{l}\text { Obtain the crown settlement trend of tunnel portal and } \\
\text { sections of tunnel exit, influence of vertical load of } \\
\text { front slope on the trend }\end{array}$ \\
\hline 4 & $\begin{array}{l}\text { Three-dimensional surface } \\
\text { displacement monit oring of } \\
\text { shallow layer in front slope }\end{array}$ & Geodetic method & $\begin{array}{l}\text { Obtain the deformation trend and stability condition of } \\
\text { in the shallow layer of front slope }\end{array}$ \\
\hline 5 & $\begin{array}{l}\text { Deep displacement } \\
\text { monitoring of front slope }\end{array}$ & $\begin{array}{l}\text { Automatic monitoring of deep } \\
\text { displacement }\end{array}$ & $\begin{array}{l}\text { Obtain the deformation trend and stability condition in } \\
\text { the deep layer of front slope }\end{array}$ \\
\hline 6 & $\begin{array}{l}\text { Settlement monitoring of } \\
\text { roof pipeline }\end{array}$ & Leveling survey & $\begin{array}{l}\text { Master the influence of portal excavation on gas } \\
\text { pipeline in tunnel roof }\end{array}$ \\
\hline
\end{tabular}




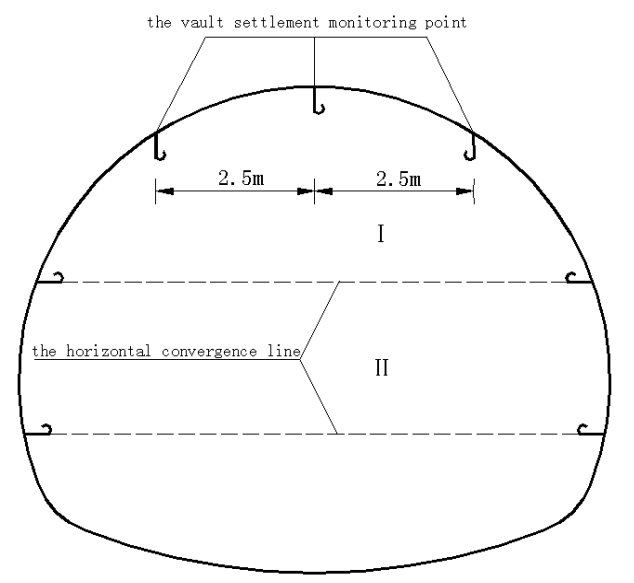

Figure 2. Measure points diagram of benching tunnelling method

4) Deep displacement monitoring of front slope:

To accurately judge the overall stability of the portal, surface displacement monitoring of shallow layer and deep displacement monitoring in front slope should be combined for comprehensively judgment. Some deep displacement monitoring points are stationed along the portal section where the front slope is vertical to the tunnel center line. Meanwhile, the other deep displacement measuring points are stationed every 5 to 10 meters in both left and right line in tunnel area. To check the three-dimensional monitoring points in shallow layer, points of deep displacement should coincide with points of displacement in shallow layer, as shown in Figure 3.

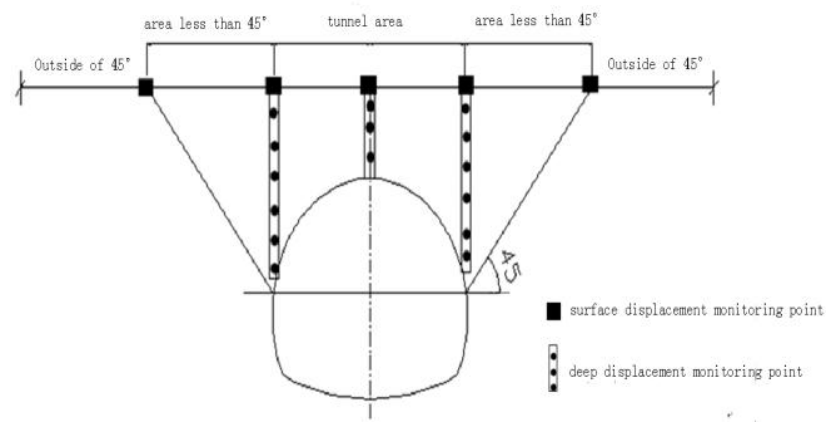

Figure 3. Diagram of measure points of surface and deep displacements in the shallow layer of front slope

5) Settlement monitoring of roof pipeline:

To master the influence of portal excavation on the natural gas pipeline in tunnel roof, subsidence monitoring points are stationed every 5 to 10 meters in the soil mass over the pipeline. The points are monitored and the influence of construction excavation on the stability is paid close attention to.

\section{E. Monitoring Frequency}

According to relevant specifications, the monitoring frequency of the projects is shown in the TABLEIV .

\section{MONITORING DATA ANALYSIS AND INFORMATION FEEDBACK}

\section{A. Monitoring Data Analysis}

Through processing and analyzing data timely, the purpose of monitoring measurement is to forecast and feedback the stability and deformation trend of threat objects, effectively guide the tunnel construction, and ensure construction safety. Taking the actual monitoring measurement data of tunnel portal excavation of the project as the analyzed object, this paper elaborates data analysis process under the multi-source data, and makes a judgment of stability and deformation trend of threat objects [6].

Gas pipeline settlement of tunnel roof: On April 22, 2016, five measurement points were arranged along the vertical profile of gas pipeline. By June 29, 2016, total 42 times daily monitoring work were conducted. TABLE III shows various points' accumulated subsidence and maximum subsidence rate. Figure 4 shows the curves of time of each point and settlement values.

TABLE III. Distortion Statistics of GAs PiPELine SETtLEMENT OFTUNNEL ROOFOF MONITORING SITES

\begin{tabular}{|c|c|c|}
\hline Point No. & $\begin{array}{c}\text { Maximum subsidence } \\
\text { rate }(\mathbf{m m} / \mathbf{d})\end{array}$ & $\begin{array}{c}\text { Accumulated subsidence } \\
(\mathbf{m m})\end{array}$ \\
\hline G1 & 1.2 & 1.8 \\
\hline G2 & 1.5 & 2.4 \\
\hline G3 & 3.4 & 6.7 \\
\hline G4 & 2.6 & 5.5 \\
\hline G5 & 1.7 & 3.5 \\
\hline
\end{tabular}

The combination of subsidence rate of each point and settlement curves shows that the deformation mainly occurred from May 5 to May 25. The main reason is that the tunnel face was close to the vertical profile of gas pipeline during construction and the construction of tunnel face had effects on gas pipeline. As tunnel face gradually moved away from the vertical profile of gas pipeline (after May 25), the deformation trended to be slowly and measure points became stable.

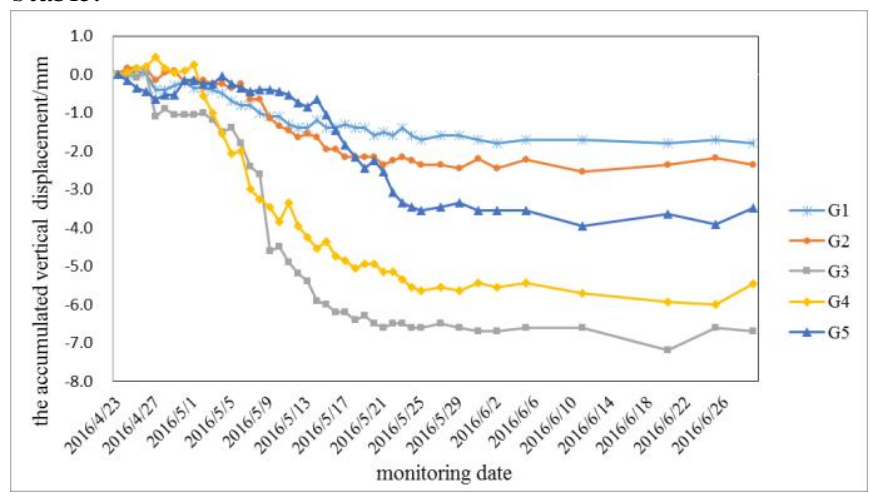

Figure 4. Time of gas pipeline settlement of monitoring points-settlement curves

Front slope of tunnel roof: The stability of the front slope of tunnel roof directly affects the construction progress and construction safety, so it is necessary to closely master the 
stability status of front slope of tunnel roof during the construction and excavation of tunnel portal and tunnel body. On April 1, 2016, 10 shallow displacement and settlement points and 5 deep displacement points were arranged along the top of the front slope of tunnel roof. The drilling depth respectively are $16 \mathrm{~m}(\mathrm{ZK} 1), 20 \mathrm{~m}(\mathrm{ZK} 2), 17 \mathrm{~m}$ (ZK3), 15m (ZK4) and 18m (ZK5). By June 29, 2016, total 66 times daily monitoring work were conducted. Due to the heavy rainfall on May 8 , the junction between the tunnel roof of front slope in right line and the side slope became obviously distorted during the subsequent days, and the tunnel roof of front slope in left line basically stayed stable. Therefore, the stability of the front slope of tunnel roof and deformation trend are judged comprehensively below by analyzing the data of 5 shallow displacement and settlement points and 3 deep displacement points of front slope of tunnel roof in right line.

Shallow displacement and settlement points (T1 - T5) of front slope of tunnel roof in right line - displacement curve and time - settlement curves are shown in Figure 5 and Figure 6 respectively.

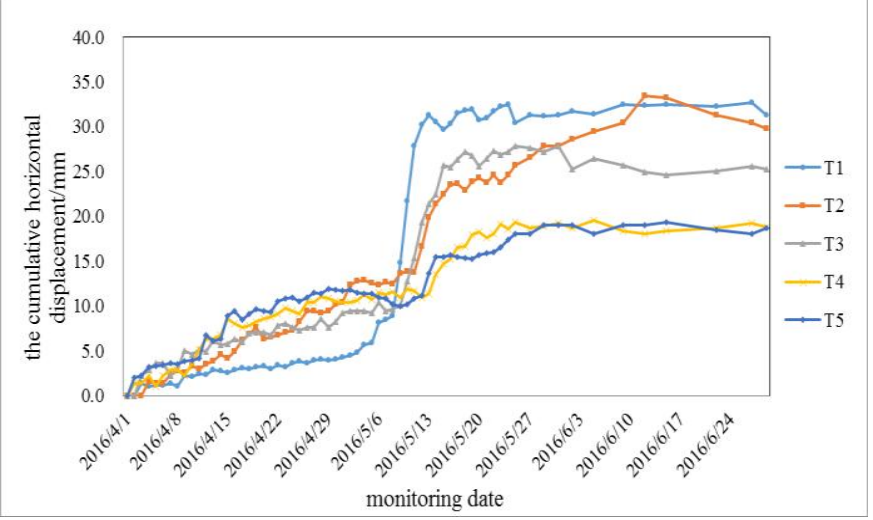

Figure 5. Time-displacement curves of measure points of shallow surface

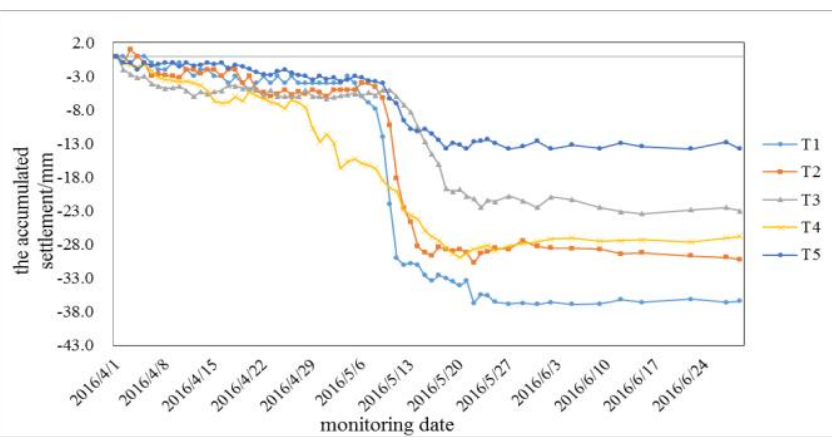

Figure 6. Time-sett lement curves of measure points of shallow surface

In order to further understand the deformation of deep rock-soil mass of the front slope, the monitoring data for $\mathrm{ZK} 1, \mathrm{ZK} 2$, and ZK3 is analy zed. By June 29, displacement curves of the deep dis placement points are shown in Figure 7.

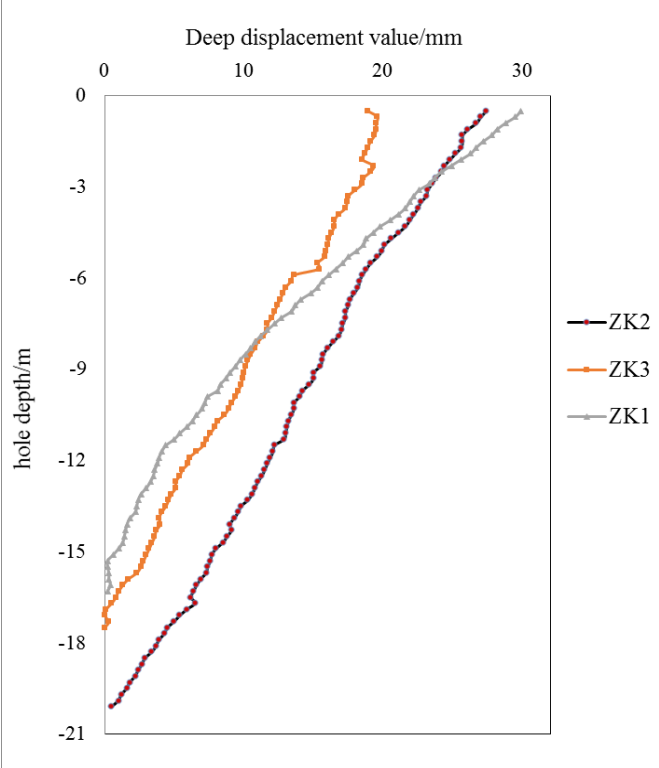

Figure 7. Deep displacement curves of front slope

TABLE IV. MONITORING FREQUENCY OF MONITORING PROJECTS

\begin{tabular}{|c|c|c|c|c|c|}
\hline \multirow{3}{*}{$\begin{array}{c}\text { Serial } \\
\text { number }\end{array}$} & \multirow{3}{*}{ Project name } & \multicolumn{4}{|c|}{ Moni toring fre quency } \\
\hline & & \multicolumn{4}{|c|}{ Monitoring time } \\
\hline & & 1-15 days & 16 days -1 months & $1-3$ mon ths & More than 3 mon ths \\
\hline 1 & $\begin{array}{l}\text { Observation of geology and support } \\
\text { condition }\end{array}$ & \multicolumn{4}{|c|}{ After each blasting and initial support } \\
\hline 2 & $\begin{array}{l}\text { Horizontal convergence monitoring of } \\
\text { portal }\end{array}$ & \multirow{2}{*}{ 1-2 times / day } & \multirow{2}{*}{1 time $/ 2$ days } & \multirow{2}{*}{ 1-2 times / week } & \multirow{2}{*}{ 1-3 times / month } \\
\hline 3 & Crown sett lement monitoring & & & & \\
\hline 4 & $\begin{array}{l}\text { Three-dimensional surface displacement } \\
\text { monitoring of shallow layer in front } \\
\text { slope }\end{array}$ & \multirow{3}{*}{\multicolumn{4}{|c|}{$\begin{array}{l}\text { The distance between excavation face and monitoring section } \leq 2 \mathrm{~B}, 1-2 \text { times / day } \\
\text { The distance between excavation face and monitoring section } \leq 5 \mathrm{~B}, 1 \text { time } / 2 \text { days } \\
\text { The distance bet ween excavation face and monitoring section }>5 \mathrm{~B}, 1 \text { time } / \text { week }\end{array}$}} \\
\hline 5 & $\begin{array}{l}\text { Deep displacement monitoring of front } \\
\text { slope }\end{array}$ & & & & \\
\hline 6 & Settlement monit oring of roof pipeline & & & & \\
\hline
\end{tabular}


TABLE V. DEFORMATION CONDITION AND TREND OFMONITORING SECTION AROUND TUNNEL PORTAL LINES

\begin{tabular}{|c|c|c|c|c|c|c|}
\hline \multirow{2}{*}{ Monitoring section } & \multicolumn{2}{|c|}{ Accumulated con ve rgence value (mm) } & \multicolumn{3}{|c|}{ Accumulated subsidence value (mm) } & \multirow{2}{*}{$\begin{array}{l}\text { Deformation } \\
\text { trend }\end{array}$} \\
\hline & Measu re line 1 & Measure line 2 & $\begin{array}{l}\text { Left Measure } \\
\text { point }\end{array}$ & vault & $\begin{array}{l}\text { Right Measure } \\
\text { point }\end{array}$ & \\
\hline $\begin{array}{l}\text { Portal of the left line } \\
\qquad(\mathrm{K} 9+695)\end{array}$ & 18.5 & 14.0 & 5.0 & 7.0 & 6.5 & $\begin{array}{l}\text { Tend to be } \\
\text { stable }\end{array}$ \\
\hline $\begin{array}{l}\text { Portal of the right line } \\
\qquad(K 9+680)\end{array}$ & 15.0 & 12.5 & 8.5 & 8.0 & 7.5 & $\begin{array}{l}\text { Tend to be } \\
\text { stable }\end{array}$ \\
\hline
\end{tabular}

The analysis of monitoring data fro $m$ the shallow layer of front slope shows that the shallow surface of the front slope in right line had significant displacement and settlement from May 8 to May 8. Meanwhile, the deformation of points (T1, T2 and T3) near the side slope was more significant. Through analysis, the soil mass at the junction between right line front slope and side slope was thicker. As a result of the consecutive heavy rainfall in the evening of May 8 , and the intercepting drain of tunnel roof being far away from here, the rain immersed into the soil, and the top of slope cracked, which led to unstable slope. After informing the construction unit about the dangerous cases by monitoring and warning, the existing cracks were timely filled and the support was reinforced. The deformation curves show that the deformation trend of the front slope surface became gentle. Meanwhile, combined with the deep displacement curves, the front slope deep surface did not slide, and no significant deformation appeared in the deep zone. Based on the analysis above, the front slope of tunnel roof is basically in a stable state without deformation development trend.

Horizontal convergence and crown settlement: In this project, since the overlying rock and soil layer of the tunnel is thin, and there is no eccentric compression in the surrounding rock around left and right tunnel lines, the vertical and horizontal loads of the tunnel body are small. Therefore, during the construction of tunnel portal, significant or sustained deformation around tunnel portal didn't occur in both left and right lines. As the tunnel face moved far away, the portal section was stable in normal conditions. By June 29, the horizontal convergence and crown settlement of the monitoring section in tunnel portal are shown in TABLE V.

\section{B. Feedback of Monitoring Information}

During the monitoring measurement of portal excavation, the establishment of a scientific and reasonable monitoring information feedback process is the safety blanket for tunnel portal and surrounding facilities. And through the feedback of the monitoring information, status quo of deformation objects can be obtained in time, providing optimized structure design, supporting parameters and construction technology with information basis, accumulating data for tunneling design and construction, and providing similar references for future design and construction [6].

Feedback of monitoring information, including monitoring results and recommendations, is informed to owners and relevant departments by weekly reports, monthly reports and summary reports, etc. When the abnormal deformation appears, owners or relevant departments should be informed by monitoring and warning in time. In addition, information feedback should be given not only between monitoring units and owners, but also between investigation and design units and construction units. When the owners are informed with the abnormal circumstances, they should transfer the relevant information to investigation and design units as well as construction units, jointly consulting for solutions when necessary.

\section{CONCLUSION}

After combining with the monitoring measurement of portal excavation of a mountain tunnel in Wanzhou, Chongqing, a complete monitoring measurement system for portal excavation is constructed, and the analysis method of tunnel portal stability based on multi-source data under the three-dimensional and multi-level monitoring system is studied. Besides, the corresponding monitoring information feedback process is given. Through the engineering practice, the following conclusions are obtained.

During the tunnel portal excavation, the selection of monitoring measurement should be based on adequate understanding of the surrounding geological and hydrological conditions, the specific risk sources, construction design and organization. It should be determined after comprehensively analysis.

The frequency of monitoring measurement shall be implemented according to the relevant specifications. When the abnormal circumstances of monitoring points appear, the monitoring frequency should be appropriately improved.

In monitoring data processing, monitoring data should be classified and processed in the form of section or profile, and the stability of deformation body should be judged according to comprehensively analysis combining with different types of monitoring.

In portal excavation of mountain tunnel, stability of the front slope and the side slope directly affect the progress and safety of construction. In the monitoring measurement, if significant fractures or progressive deformations appear, the fractures should be closed and filled timely to reduce rainwater infiltration. And drainage and interception of the roof should be conducted. Meanwhile, support of front slope should be strengthened.

In the monitoring measurement, if abnormal deformation appears, owners and construction units should be informed by monitoring and warning. Monitoring information feedback should be conducted in time. 


\section{ACKNOWLEDGMENT}

Foundation support: Chongqing technology research and demonstration platform of Geological disasters intelligent monitoring (cstc2015pt-kjyfsf0017).

Urban geological survey of Chongqing metropolitan economic circle (1212011220032), China Geological Survey.

\section{REFERENCES}

[1] WANG Mengshu. Tunnel and underground engineering construction and technology of China. Beijing: China Communications Press, 2010.

[2] MI Shiwen, GONG Shulin. Tunnel monitoring measurement data processing and analysis. Science and technology in western China, 2010, 09(01): 32-33+50
[3] QIN Zhifu, TANG Jian. Monitoring and measurement of expressway tunnel and its application. Technology of Highway and Transport, 2006(2):99-104.

[4] The ministry of railways of the People's Republic of China. Railway tunnel monitoring technology procedures. Beijing, China Railway Press, 2007.

[5] WEI Shiyu. Research and application of new austrian tunneling method tunnel deformation monitoring system.Chongqing: Chongqing university, 2013.

[6] YE Fei, DING Wenqi, ZHU Hehua, et al. Highway tunnel site monitoring and information feedback. Journal of chang 'an university, 2007(05):79-83. 